\title{
ERRATUM
}

Jesper Graakjaer · Héra Der-Sarkissian

Annette Schmitz • Jan Bayer • Gilles Thomas

Steen Kolvraa · José-Arturo Londoño-Vallejo

\section{Allele-specific relative telomere lengths are inherited}

Published online: 1 March 2006

(C) Springer-Verlag 2006

\section{Hum Genet (2006) DOI 10.1007/s00439-006-0137-x}

The e-mail address of the corresponding author was incorrect. It should read: Jose-Arturo.Londono-Vallejo@curie.fr.

The online version of the original article can be found at http:// dx.doi.org/10.1007/s00439-006-0137-x

J. Graakjaer · J.-A. Londoño-Vallejo $(\bowtie)$

Telomeres and Cancer Lab, UMR7147, CNRS-I, Curie-UPMC,

Paris, France

E-mail: Jose-Arturo.Londono-Vallejo@curie.fr

J. Graakjaer

Institute for Human Genetics, University of Aarhus,

Aarhus, Denmark

H. Der-Sarkissian · J. Bayer · G. Thomas

Fondation Jean Dausset CEPH, Paris, France

A. Schmitz

Commissariat à l'Energie Atomique, Fontenay-aux-Roses,

France

S. Kolvraa

Department of Clinical Genetics, Vejle Hospital, Vejle,

Denmark 